\title{
Corpus Callosum and Cingulum Tractography in Parkinson's Disease
}

\author{
Katie Wiltshire, Luis Concha, Myrlene Gee, Thomas Bouchard, \\ Christian Beaulieu, Richard Camicioli
}

\begin{abstract}
Background: In Parkinson's disease (PD) cell loss in the substantia nigra is known to result in motor symptoms; however widespread pathological changes occur and may be associated with non-motor symptoms such as cognitive impairment. Diffusion tensor imaging is a quantitative imaging method sensitive to the micro-structure of white matter tracts. Objective: To measure fractional anisotropy (FA) and mean diffusivity (MD) values in the corpus callosum and cingulum pathways, defined by diffusion tensor tractography, in patients with PD, PD with dementia (PDD) and controls and to determine if these measures correlate with Mini-Mental Status Examination (MMSE) scores in parkinsonian patients. Methods: Patients with PD (17 Males [M],12 Females [F]), mild PDD (5 $\mathrm{M}, 1 \mathrm{~F})$ and controls $(8 \mathrm{M}, 7 \mathrm{~F})$ underwent cognitive testing and MRI scans. The corpus callosum was divided into four regions and the cingulum into two regions bilaterally to define tracts using the program DTIstudio (Johns Hopkins University) using the fiber assignment by continuous tracking algorithm. Volumetric MRI scans were used to measure white and gray matter volumes. Results: Groups did not differ in age or education. There were no overall FA or MD differences between groups in either the corpus callosum or cingulum pathways. In PD subjects the MMSE score correlated with MD within the corpus callosum. These findings were independent of age, sex and total white matter volume. Conclusions: The data suggest that the corpus callosum or its cortical connections are associated with cognitive impairment in PD patients.
\end{abstract}

RÉSUMÉ: La tractographie du corps calleux et du cingulum dans la maladie de Parkinson. Contexte : Dans la maladie de Parkinson, il est bien connu que la perte cellulaire dans le locus niger cause des symptômes moteurs; cependant, il se produit des changements anatomopathologiques étendus qui peuvent être associés à des symptômes qui ne sont pas moteurs tels une atteinte cognitive. L'imagerie en tenseur de diffusion est une méthode d'imagerie quantitative qui est sensible à la microstructure des faisceaux de la substance blanche. Objectif : Le but de l'étude était de mesurer l'anisotropie fractionnelle (AF) et la diffusivité moyenne (DM) dans les voies du corps calleux et du cingulum, définies par la tractographie en tenseur de diffusion, chez des patients atteints de la MP, de la MP accompagnée de démence (MPD) et chez des témoins, et d'évaluer si ces mesures son corrélées avec les scores au Mini-Mental Status Examinassions (MMSE) chez des patients parkinsoniens. Méthodes : Des patients atteints de la MP (17 hommes et 12 femmes), de la MPD (5 hommes et 1 femme et des témoins ( 8 hommes et 7 femmes) ont subi une évaluation cognitive et des scans par IRM. Le corps calleux était divisé en quatre régions et le cingulum en deux régions bilatéralement pour définir les voies au moyen du programme DTIstudio (Johns Hopkins University) utilisant l'algorithme de "tracking" de fibres continu pour l'organisation des faisceaux. Des scans IRM volumétriques ont été utilisés pour mesurer le volume de la substance blanche et de la substance grise. Résultats : L'âge et le niveau de scolarité des différents groupes étaient semblables. Il n'y avait pas de différences de FA ou de MD entre les groupes dans les voies du corps calleux ou du cingulum. Chez les sujets atteints de la MP, les scores au MMSE étaient corrélés à la MD dans le corps calleux. Ces observations étaient indépendantes de l'âge, du sexe et du volume total de la substance blanche. Conclusions : Selon ces données, le corps calleux ou ses connections corticales sont associés à l'atteinte cognitive chez les patients atteints de la MP.

Can. J. Neurol. Sci. 2010; 37: 595-600

Parkinson's disease (PD) is a common progressive neurodegenerative movement disorder. Although motor symptoms are associated with focal loss of substantia nigra dopaminergic neurons, pathological changes in PD are widespread $^{1}$. Dementia in patients with PD is common and patients with Parkinson's disease and dementia (PDD) have involvement of additional cortical regions compared with nondemented PD patients ${ }^{2}$. While PD is not known to directly affect white matter fiber tracts, changes in these tracts may reflect pathology within the neuronal cell bodies from which the axons arise and PDD patients may show different patterns of white matter involvement than PD patients.

Diffusion tensor imaging (DTI) non-invasively measures the anisotropic mobility of water in the human brain ${ }^{3}$, which provides an indirect quantitative marker of the micro-structural "integrity" (e.g. axon packing, myelin) of white matter tracts, such as the corpus callosum and the cingulum ${ }^{4}$. Two commonly reported diffusion parameters are mean diffusivity (MD), an estimate of the overall bulk diffusivity irrespective of orientation and fractional anisotropy (FA) representing the degree of

\footnotetext{
From the Glenrose Rehabilitation Hospital, Edmonton, Alberta, Canada.

Received October 9, 2009. Final Revisions Submitted March 9, 2010.

Correspondence to: Richard Camicioli, E223 Glenrose Rehabilitation Hospital, 10120-111th Avenue, Edmonton, Alberta, T5G 0B7, Canada.
} 
directionality of water molecule motion. Two methods of determining regional FA and $\mathrm{MD}$ in specific tracts are manual region of interest (ROI) analysis and tractography. Region of interest analysis enables the measurement of FA and MD at predefined locations on particular slices of a magnetic resonance image. Tractography reconstructs individual white matter fiber tracts based on a priori knowledge of brain anatomy and enables the quantitative analysis of diffusion parameters over the entire length of the tract ${ }^{5}$.

Studies using DTI ROI analysis have shown that PD patients have decreased FA values in areas connected to the substantia nigra and premotor cortex ${ }^{6}$, as well as directly within the substantia nigra ${ }^{7}$. These findings are consistent with the known pathology that occurs in the substantia nigra of PD patients.

In addition to substantia nigra involvement, frontal cortical atrophy has been shown in PD patients with additional cortical involvement in PDD patients as determined by conventional magnetic resonance imaging (MRI) methods ${ }^{2}$. Diffusion tensor imaging ROI analysis has shown reduced FA values in frontal, temporal, and occipital white matter in both PD and PDD patients $^{8}$. In addition, FA reduction is present in the posterior cingulum white matter of PDD versus PD patients ${ }^{8}$ suggesting that cognitive function may be related to diffusion abnormalities in the cingulum pathway. Patients with Dementia with Lewy Bodies, which overlaps pathologically with $\mathrm{PDD}^{9}$, have decreased FA and increased MD in the corpus callosum and pericallosal regions ${ }^{10}$ suggesting that PDD patients may have similar changes in the corpus callosum. The area of the corpus callosum, as measured on mid-sagittal MRI, is not reduced in patients with PD or PDD ${ }^{11}$; however DTI may be more sensitive at detecting white matter changes compared to atrophy measures. Tractography has not been used to examine the involvement of the cingulum or corpus callosum in this patient population. Tractography provides the ability to average FA and MD values over the length of a tract, possibly helping to reduce sampling error, which may occur with ROI analysis.

In this study we examined the corpus callosum and cingulum pathways using DTI tractography in patients with PD or PDD to determine if subtle pathologic changes are present in these white matter tracts. The purpose of our study was to determine if subtle white matter changes might be evident in this classical "subcortical" disease. Moreover, we examined if FA or MD measurements within the corpus callosum and cingulum are associated with cognitive function.

\section{MeTHODS}

Patient Selection: Patients and controls were recruited from the Movement Disorders Clinic at the University of Alberta, the Parkinson Society of Alberta, posters in seniors centers, advertisements placed in senior's newsletters and by word of mouth. Parkinson's disease patients were consecutively recruited and, like controls, were in stable health and did not have a clinical health condition that could compromise survival. Parkinson's disease patients met criteria for idiopathic PD ${ }^{12}$. Patients with atypical clinical features or incidental stroke on structural imaging were excluded. Patients with PDD first had parkinsonism and subsequently developed dementia as defined by DSM-IV criteria ${ }^{13}$. All patients and controls underwent cognitive testing using the Mini-Mental Status Examination $(\mathrm{MMSE})^{14}$-a quantitative measurement of multiple domains of cognition. Disease severity was assessed using the United Parkinson's Disease Rating Scale (UPDRS, part 3) ${ }^{15}$.

Scan Protocol: Magnetic resonace imaging was performed on a $1.5 \mathrm{~T}$ Siemens Sonata scanner. Volumetric scans were obtained using a coronal magnetization prepared rapid acquisition sequence oriented perpendicular to the anteriorposterior commissure line (MPRAGE: TR $1800 \mathrm{~ms}$, TE $3.82 \mathrm{ms,}$ TI $1100 \mathrm{~ms}, 1$ average, flip angle $=15$ degrees, FOV $=256 \mathrm{~mm}$, image matrix 256X256, 128 coronal slices, $1.5 \mathrm{~mm}$ slice thickness) and processed as previously described ${ }^{16}$. Volumes were calculated for gray matter (GM) and white matter (WM) segments using the "spm_get_volumes" function in SPM5 (Welcome Department of Cognitive Neurology, London, UK, http://www.fil.ion.ucl.ca.uk/spm), as described ${ }^{16}$. In addition standard axial T2 and FLAIR scans were used to exclude pathological lesions ${ }^{17}$. Slices for DTI acquisition were aligned axially along the inferior margin of the corpus callosum using a T1 weighted multi-slice sagittal image and placed such that the vertex was included. The DTI data was acquired using the following parameters: slice thickness $=3 \mathrm{~mm}$, no inter-slice gap, $\mathrm{TR}=5600 \mathrm{~ms}, \mathrm{TE}=88 \mathrm{~ms}$, $\mathrm{FOV}=220 \times 220 \mathrm{~mm}^{2}$, acquisition matrix $=128 \times 128$ with $75 \%$ phase partial Fourier (interpolated to $256 \times 256$ ), six diffusion directions, $b=1000 \mathrm{~s} / \mathrm{mm}^{2}$, acquisition voxel size of $1.7 \times 1.7 \times 3.0 \mathrm{~mm}^{3}$ (interpolated to $0.86 \times 0.86 \times 3.0$ $\mathrm{mm}^{3}$ ), 35 slices, eight averages for a total scan time of 5 minutes and 21 seconds. Motion artifact was assessed visually using source images, and was not found to be prominent in any of the images; hence motion correction was not applied. Images were not warped for DTI or volumetric measurements, but were analyzed in native space.

Deterministic Fiber Tracking: Processing was performed using the program DTIstudio (Johns Hopkins University) using the fiber assignment by continuous tracking algorithm ${ }^{18}$. Fibers were included if their FA value was $>0.3$ and the turning angle between voxels was $<70$ degrees eliminating the analysis of cerebrospinal fluid (CSF) and grey matter, as well as minimizing spurious fibers. An in-house program built on Matlab 7 (The Mathworks, Natick, MA) was used to determine FA and MD values. All of the voxels included in each tract were queried for DTI parameters and averaged - each voxel was only counted once.

Corpus Callosum Tractography: Four regions of the corpus callosum were evaluated (CC1-CC4). Individual regions of the corpus callosum are derived from separate areas of the cortex and therefore anterior to posterior differences may exist within the corpus callosum itself. Methods of division of the corpus callosum were based on methods outlined in our previous volumetric study ${ }^{11}$. Fibers were required to course through the pre-selected area of the corpus callosum on the mid-sagittal image and continue to a point distal to the corpus callosum as described in Figure 1.

Cingulum Tractography: The cingulum was divided into two regions bilaterally. Fiber tracts were required to traverse the most distal points of each segment as well as a point located midway (Figure 2). Left and right tracts were analyzed separately and values were averaged over the defined area of interest.

Statistical Methods: Groups were compared using an analysis of variance. Post hoc comparisons were done using a Bonferonni correction when there were group differences. Intrarater reliability for measurements were determined by the re- 


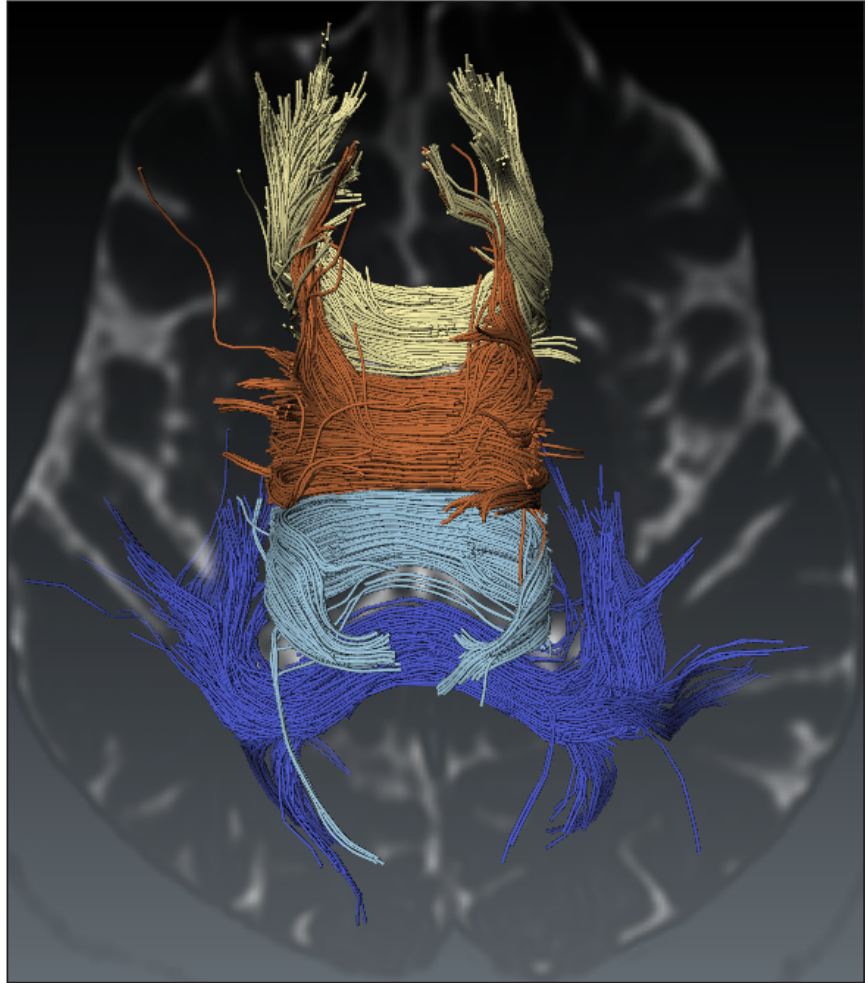

Figure 1: Corpus Callosum Tractography: For fibers arising in segment CC1 (anterior $=$ yellow) only fibers projecting anteriorly and traversing the coronal slice at the most anterior point of the corpus callosum were included and fibers were excluded if they projected posterior to the traced region. For areas $C C 2$ (anterior body = orange) and CC3 (posterior body $=$ light blue), only fibers passing through the most superior point of the traced region on the horizontal slice were included and fibers were excluded if they projected inferiorly. For area CC4 (posterior $=$ dark blue), fibers not projecting to the occipital or temporal lobes were excluded.

tracing of six randomly chosen subjects using single measure interclass correlation coefficients (ICCs), using a two way mixed model with absolute agreement ${ }^{19}$. The relationship between MMSE and FA or MD values in the corpus callosum and cingulum were determined in PD and PDD patients as one group. Partial correlation coefficients, controlling for age and sex were reported. The impact of white matter volume on partial correlation coefficients was also examined. A p-value of 0.05 was considered statistically significant.

\section{RESULTS}

\section{Subject Characteristics}

The baseline characteristics of the subjects are reported in Table 1. There was no difference between the PD, PDD, and control groups in age, education, or whole brain grey or white matter using a one-way analysis of variance. Post hoc tests revealed significantly lower MMSE scores in the PDD group than in the control or PD groups $(p<0.05)$. Parkinson's disease and PDD groups had significantly higher UPDRS scores than controls, as expected $(\mathrm{p}<0.05)$.

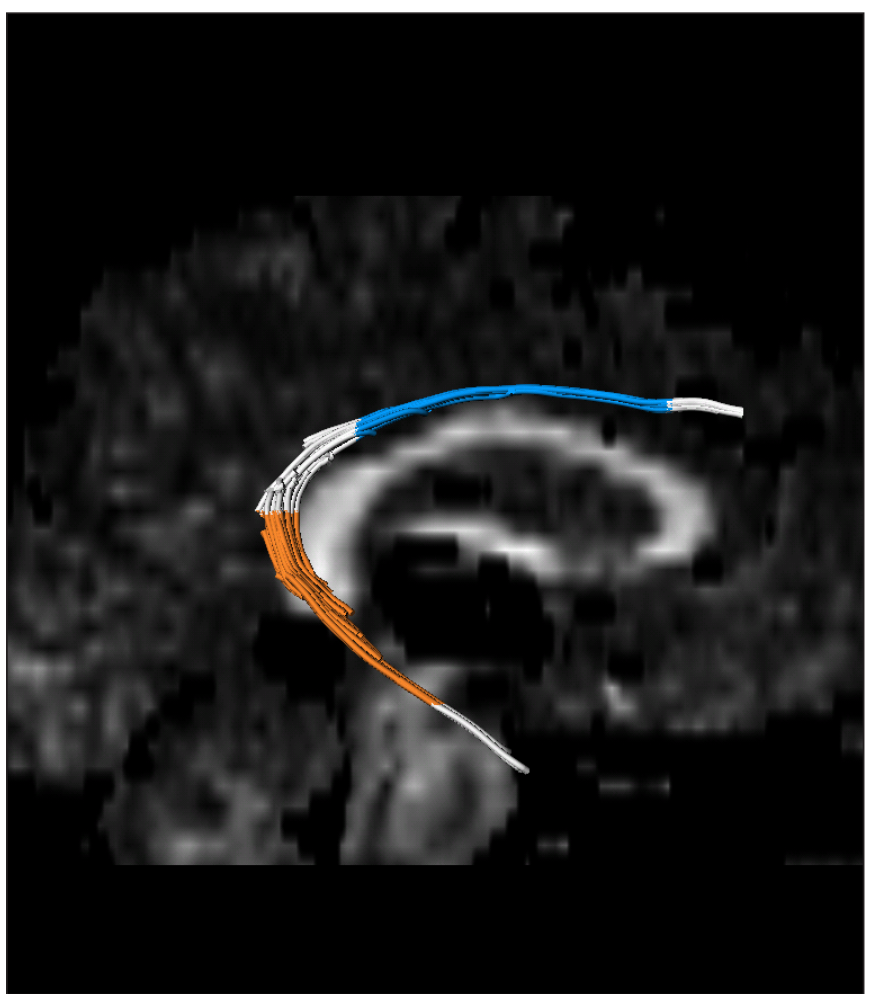

Figure 2: Cingulum Tractography. The following landmark parameters were used: 1. Body: the portion of the cingulum coursing posteriorly from the most posterior point of the rostrum to the most anterior point of the splenium (blue). 2. Posterior: the portion of the cingulum coursing inferiorly and laterally from the most superior point of the fornix to the level of the midbrain (orange). FA and MD values were calculated for fibers contained within the specified regions bilaterally.

\section{DTI Measurements}

Intra-class correlation coefficients (ICC's) for FA values were 0.97-1.0 (corpus callosum), and 0.67-0.87 (cingulum). Intraclass correlation coefficients for MD values were 0.88-1.0 (corpus callosum) and 0.87-0.95 (cingulum).

Corpus callosum (Table 2) and cingulum (Table 3) tractography revealed no significant difference in FA or MD values between groups. Fractional anisotropy values in all groups were lower than traditionally seen in DTI ROI analysis as the FA values obtained with tractography are averages of the entire tract and include tract extension into the gyral white matter.

\section{DTI Correlations with MMSE}

Tractography of the corpus callosum revealed correlations of MMSE with MD values in all regions of the corpus callosum $(p<0.05)$, which remained significant in three of the regions, namely the two anterior and the posterior regions of the corpus callosum (Table 4) in models controlling for age and sex. These correlations were unaltered by controlling for WM volume. Scatterplots indicated that subgroups of subjects did not drive the correlations (data not shown). Tractography of the cingulum was not significantly correlated with MMSE (data not shown). 
Table 1: Baseline subject characteristics*

\begin{tabular}{l|l|l|l|l|l|l|l}
\hline & $\begin{array}{l}\text { Gender } \\
\text { (male, } \\
\text { female) }\end{array}$ & $\begin{array}{l}\text { Age (years) } \\
(\mathrm{SD})\end{array}$ & $\begin{array}{l}\text { Education } \\
\text { (years) }(\mathrm{SD})\end{array}$ & $\begin{array}{l}\text { MMSE } \\
(\mathrm{SD})\end{array}$ & $\begin{array}{l}\text { UPDRS III } \\
(\mathrm{SD})\end{array}$ & $\begin{array}{l}\text { Whole Brain } \\
\text { GM volume } \\
(\mathrm{mL}) \\
(\mathrm{SD})\end{array}$ & $\begin{array}{l}\text { Whole Brain } \\
\text { WM volume } \\
(\mathrm{mL}) \\
(\mathrm{SD})\end{array}$ \\
\hline $\begin{array}{l}\text { Controls } \\
(\mathrm{n}=15)\end{array}$ & 8,7 & $70.7(4.0)$ & $16.2(2.5)$ & $\begin{array}{l}28.8 \\
(1.1)\end{array}$ & $1.4(2.0)$ & $636(70)$ & $460(61)$ \\
\hline $\begin{array}{l}\mathrm{PD} \\
(\mathrm{n}=29)\end{array}$ & 17,12 & $70.8(4.6)$ & $14.3(3.4)$ & $\begin{array}{l}28.4 \\
(1.5)\end{array}$ & $16.8(7.6)$ & $623(58)$ & $526(49)$ \\
\hline $\begin{array}{l}\mathrm{PDD} \\
(\mathrm{n}=6)\end{array}$ & 5,1 & $71.4(4.2)$ & $13.7(1.9)$ & $\begin{array}{l}25.7 \\
(1.8)\end{array}$ & $19.5(8.5)$ & $650(65)$ & $526(98)$ \\
\hline $\mathrm{P}$ value & 0.4 & 0.95 & 0.10 & $<0.05$ & $<0.05$ & 0.58 & 0.08 \\
\hline F (2,49) & NA & 0.06 & 2.42 & 10.99 & 30.7 & 0.55 & 2.74 \\
\hline
\end{tabular}

*SD-Standard Deviation; PD-Parkinson's disease; PDD-Parkinson's disease with dementia; MMSE-Mini-Mental Status Examination; UPDRS-Unified Parkinson's Disease Rating Scale

Table 2: Group comparison of tractography derived DTI parameters for four regions of the corpus callosum.*

\begin{tabular}{|c|c|c|c|c|c|c|c|c|}
\hline & \multicolumn{2}{|c|}{$\mathrm{CC} 1$} & \multicolumn{2}{|c|}{$\mathrm{CC} 2$} & \multicolumn{2}{|c|}{$\mathrm{CC} 3$} & \multicolumn{2}{|r|}{$\mathrm{CC} 4$} \\
\hline & $\begin{array}{l}\text { FA } \\
(\mathrm{SD})\end{array}$ & $\begin{array}{l}\mathrm{MD} \\
\left(10^{-3} \mathrm{~mm}^{2} / \mathrm{s}\right) \\
(\mathrm{SD})\end{array}$ & $\begin{array}{l}\text { FA } \\
(\mathrm{SD})\end{array}$ & $\begin{array}{l}\mathrm{MD} \\
\left(10^{-3} \mathrm{~mm}^{2} / \mathrm{s}\right) \\
(\mathrm{SD})\end{array}$ & $\begin{array}{l}\text { FA } \\
\text { (SD) }\end{array}$ & $\begin{array}{l}\mathrm{MD} \\
\left(10^{-3} \mathrm{~mm}^{2} / \mathrm{s}\right) \\
(\mathrm{SD})\end{array}$ & $\begin{array}{l}\text { FA } \\
(\mathrm{SD})\end{array}$ & $\begin{array}{l}\mathrm{MD} \\
\left(10^{-3} \mathrm{~mm}^{2} / \mathrm{s}\right) \\
(\mathrm{SD})\end{array}$ \\
\hline $\begin{array}{l}\text { Control } \\
(n=14)\end{array}$ & $\begin{array}{l}0.54 \\
(0.02)\end{array}$ & $0.77(0.04)$ & $\begin{array}{l}0.56 \\
(0.03)\end{array}$ & $0.83(0.05)$ & $\begin{array}{l}0.58 \\
(0.03)\end{array}$ & $0.83(0.05)$ & $\begin{array}{l}0.57 \\
(0.01)\end{array}$ & $0.86(0.05)$ \\
\hline $\begin{array}{l}\mathrm{PD} \\
(\mathrm{n}=29)\end{array}$ & $\begin{array}{l}0.54 \\
(0.02) \\
\end{array}$ & $0.79(0.05)$ & $\begin{array}{l}0.56 \\
(0.02) \\
\end{array}$ & $0.83(0.06)$ & $\begin{array}{l}0.58 \\
(0.03) \\
\end{array}$ & $0.83(0.07)$ & $\begin{array}{l}0.58 \\
(0.02) \\
\end{array}$ & $0.86(0.04)$ \\
\hline $\begin{array}{l}\text { PDD } \\
(n=6)\end{array}$ & $\begin{array}{l}0.53 \\
(0.02)\end{array}$ & $0.80(0.04)$ & $\begin{array}{l}0.58 \\
(0.02)\end{array}$ & $0.87(0.09)$ & $\begin{array}{l}0.61 \\
(0.04)\end{array}$ & $0.86(0.07)$ & $\begin{array}{l}0.57 \\
(0.02)\end{array}$ & $0.89(0.07)$ \\
\hline P-value & 0.63 & 0.44 & 0.32 & 0.35 & 0.06 & 0.59 & 0.70 & 0.27 \\
\hline $\mathrm{F}(2,48)$ & 0.46 & 0.83 & 1.17 & 1.08 & 3.07 & 0.53 & 0.35 & 1.35 \\
\hline
\end{tabular}

*SD-Standard Deviation; PD-Parkinson's disease; PDD-Parkinson's disease with dementia; FA-fractional anisotropy; MD-mean diffusivity; CC 1 (anterior) - CC4 (posterior) - corpus callosum subregions (see Figure 1)

Table 3: Group comparison of tractography derived DTI parameters for two regions of the cingulum*

\begin{tabular}{l|l|l|l|l|l|l|l|l}
\hline & \multicolumn{2}{|c|}{ Left Body } & \multicolumn{2}{c|}{ Right Body } & \multicolumn{2}{c}{ Left Posterior } & \multicolumn{2}{c}{ Right Posterior } \\
\hline & $\begin{array}{l}\text { FA } \\
(\mathrm{SD})\end{array}$ & $\begin{array}{l}\text { MD } \\
\left(10^{-3} \mathrm{~mm}^{2} / \mathrm{s}\right) \\
(\mathrm{SD})\end{array}$ & $\begin{array}{l}\text { FA } \\
(\mathrm{SD})\end{array}$ & $\begin{array}{l}\text { MD } \\
\left(10^{-3} \mathrm{~mm}^{2} / \mathrm{s}\right) \\
(\mathrm{SD})\end{array}$ & $\begin{array}{l}\text { FA } \\
(\mathrm{SD})\end{array}$ & $\begin{array}{l}\text { MD } \\
\left(10^{-3} \mathrm{~mm}^{2} / \mathrm{s}\right) \\
(\mathrm{SD})\end{array}$ & $\begin{array}{l}\text { FA } \\
(\mathrm{SD})\end{array}$ & $\begin{array}{l}\text { MD } \\
\left(10^{-3} \mathrm{~mm}^{2} / \mathrm{s}\right) \\
(\mathrm{SD})\end{array}$ \\
\hline $\begin{array}{l}\text { Control } \\
(\mathrm{n}=15)\end{array}$ & $\begin{array}{l}0.61 \\
(0.04)\end{array}$ & $0.76(0.03)$ & $\begin{array}{l}0.61 \\
(0.04)\end{array}$ & $0.75(0.03)$ & $\begin{array}{l}0.50 \\
(0.03)\end{array}$ & $0.78(0.08)$ & $\begin{array}{l}0.51 \\
(0.02)\end{array}$ & $0.77(0.04)$ \\
\hline $\begin{array}{l}\mathrm{PD} \\
(\mathrm{n}=28)\end{array}$ & $\begin{array}{l}0.62 \\
(0.05)\end{array}$ & $0.73(0.03)$ & $\begin{array}{l}0.60 \\
(0.05)\end{array}$ & $0.73(0.02)$ & $\begin{array}{l}0.49 \\
(0.03)\end{array}$ & $0.78(0.04)$ & $\begin{array}{l}0.50 \\
(0.03)\end{array}$ & $0.78(0.05)$ \\
\hline $\begin{array}{l}\text { PDD } \\
(\mathrm{n}=6)\end{array}$ & $\begin{array}{l}0.59 \\
(0.03)\end{array}$ & $0.74(0.02)$ & $\begin{array}{l}0.58 \\
(0.06)\end{array}$ & $0.73(0.02)$ & $\begin{array}{l}0.48 \\
(0.03)\end{array}$ & $0.81(0.07)$ & $\begin{array}{l}0.50 \\
(0.01)\end{array}$ & $0.81(0.06)$ \\
\hline P-value & 0.50 & 0.08 & 0.42 & 0.28 & 0.31 & 0.61 & 0.29 & 0.28 \\
\hline F (2,48) & 0.70 & 2.68 & 0.88 & 1.31 & 1.19 & 0.50 & 1.29 & 1.31 \\
\hline
\end{tabular}

*SD-Standard Deviation; PD-Parkinson's disease; PDD-Parkinson's disease with dementia; FA-fractional anisotropy; MDmean diffusivity 


\section{DiscuSSION}

Tractography is a relatively new imaging technique that enables the quantitative analysis of white matter fiber tracts. Given that the corpus callosum is composed of axons arising from cortical neurons and that cortical atrophy ${ }^{2}$ and subcortical DTI ROI changes ${ }^{8}$ have been found in PD and PDD patients, we hypothesized that tractography of the corpus callosum in PD and PDD patients would reveal abnormal FA and MD values; however no differences were found between groups. In addition, DTI ROI analysis has shown decreased FA values in the posterior cingulum in PDD patients compared with PD patients ${ }^{8}$. Based on this we expected to find alterations in the cingulum pathways using tractography. Our data did not support these findings directly; however, in the previous DTI ROI studies, disease severity in PD and PDD groups and dementia severity in the PDD groups were greater than in our study. White matter microstructural changes may not be robust in early stages of dementia; however our study found correlations with the MMSE score suggesting that cognitively meaningful changes may be reflected by our DTI measures. Given our previous study that did not find a correlation between MMSE and callosal area, these new data suggest that DTI may be more sensitive than gross structural measures of the callosum to changes in trans-callosal pathways $^{11}$.

Among PD and PDD patients, tractography revealed negative correlations between MD values of the two anterior regions and the posterior region of the corpus callosum and cognitive function, as measured by the MMSE. Increased MD, indicating greater tissue disruption, was correlated with lower MMSE scores. There were no correlations between the cingulum FA and MD values and MMSE. This suggests that cognitive decline in patients with parkinsonism may be related to global cortical changes, rather than changes in hippocampal connections. We combined PD and PDD patients in our correlation analysis in order to examine the spectrum of patients with cognitive dysfunction. One group that showed correlation between parietal FA and executive function (using a ROI approach) ${ }^{20}$ found an association between DTI measures in the posterior cingulum with dementia ${ }^{8}$ and the anterior cingulum with depression in $\mathrm{PD}^{21}$ highlighting the possibility that DTI measures might provide a window into the neural basis for clinical heterogeneity in PD.

Several additional recent studies add further support to involvement of white matter tracts in PD. One study using an ROI approach found frontal and parietal white matter changes ${ }^{22}$ while another showed global changes using DTI that were apparent in patients with greater motor impairment ${ }^{23}$. Another study supported involvement of the frontal lobes in patients with $\mathrm{PD}^{24}$. Early involvement of olfactory pathways was observed in a study focusing on the olfactory tract in $\mathrm{PD}^{25}$. Interestingly, one group found that olfactory function was associated with orbitofrontal and cerebellar DTI measures ${ }^{26}$. Coupled with recently confirmed evidence that DTI at 3.0 Tesla shows substantia nigra changes in PD compared to controls ${ }^{27,28}$ our data and the other recent literature suggest that there are DTI changes in PD in both grey and white matter that may be behaviorally meaningful.

While tractography offers the advantage of defining degeneration along specific tracts of interest, as shown for connections of the pedunculopontine nucleus in healthy controls and primates ${ }^{29}$, it provides averaged FA and MD values for an entire tract and therefore might miss changes in a specific portion of a tract. Our data illustrates that measurement of different tracts may have differences in measurement reliability; callosal reliability was slightly higher than that for the cingulum using our protocol. Improvements in DTI acquisition technology may further improve reliability ${ }^{30}$. Another consideration in interpreting our findings is that even though our sample size was large compared to the majority of DTI studies, we had relatively few PDD subjects (i.e., six), which would reduce power to see a small difference between groups. Future studies examining more subjects with a range in cognitive performance with more refined cognitive tests are necessary.

Reasons for the lack of correlation between FA and MMSE are unclear; however, MD and FA provide completely independent descriptors of the diffusion ellipse, such that MD reflects overall bulk diffusivity (i.e. volume of the ellipse) while FA measures the degree of directionality (i.e. how different the long and short axes of the ellipse are from one another). One could have increased MD with normal FA if there were selective axonal loss (and/or alterations in the extra-cellular matrix) and the axons remaining were large and modestly separated from each other. This would give water more room to diffuse in all directions, while remaining healthy axons could still drive anisotropy. Our findings in PD/PDD reflect increased diffusivity with preservation of the directionality of diffusion. While animal studies report increased MD and decreased FA with total demyelination, without pathological specimens it is not known what the elevated MD might reflect at the microstructural level. Interestingly, our results are consistent with studies in Alzheimer disease where MMSE was correlated with MD but not with FA in the posterior cingulate region ${ }^{31,32}$.

Table 4: Partial correlation coefficients of corpus callosum tractography measures with MMSE, controlling for age and sex

\begin{tabular}{l|l|l|l|l|l|l|l|l}
\hline & \multicolumn{2}{|c|}{ CC1 } & \multicolumn{2}{c|}{ CC2 } & \multicolumn{2}{c}{ CC3 } & \multicolumn{2}{c}{ CC4 } \\
\hline & FA & MD & FA & MD & FA & MD & FA & MD \\
\hline $\begin{array}{l}\mathbf{R}, \mathbf{D F} \\
\mathbf{3 1}\end{array}$ & 0.205 & -0.36 & 0.032 & -0.51 & -0.16 & -0.19 & 0.186 & -0.39 \\
\hline $\mathbf{P}$ & & & & & & & & \\
\hline
\end{tabular}




\section{Conclusions}

In conclusion, our study examined the corpus callosum and cingulum pathways using tractography in PD and PDD patients. While PD and PDD patients did not show group changes in FA or MD within the corpus callosum or cingulum, correlation of the DTI measure mean diffusivity in the corpus callosum with MMSE was identified. Given these associations, which were exploratory, additional studies examining a broader range of cognitively impaired PD patients may reveal additional white matter pathology such as that seen in patients with dementia with Lewy bodies ${ }^{10}$.

\section{ACKNOWLEDGMENTS}

The study was supported by the Canadian Institutes for Health Research (CIHR). Pfizer Canada and Johnson and Johnson Canada provided funds for scanning the patients with dementia as part of investigator-initiated studies. Katie Wiltshire was supported by Alberta Heritage Foundation for Medical Research (AHFMR) summer studentships. Dr. Beaulieu is supported by AHFMR. Dr. Concha was supported by Propem.

The authors thank the staff of the movement disorders clinic for support and help with subject recruitment and the research staff and MR technologists who assisted with data collection.

\section{REFERENCES}

1. Braak H, Muller CM, Rub U, Ackermann H, Bratzke H, de Vos RA, et al. Pathology associated with sporadic Parkinson's disease-where does it end? J Neural Transm Suppl. 2006;(70):89-97.

2. Burton EJ, McKeith IG, Burn DJ, Williams ED, O'Brien JT. Cerebral atrophy in parkinson's disease with and without dementia: a comparison with Alzheimer's disease, dementia with lewy bodies and controls. Brain. 2004;127(Pt 4):791-800.

3. Basser PJ, Mattiello J, LeBihan D. MR diffusion tensor spectroscopy and imaging. Biophys J. 1994;66(1):259-67.

4. Beaulieu C. The basis of anisotropic water diffusion in the nervous system - a technical review. NMR Biomed. 2002;15(7-8): 435-55.

5. Mori S, Zhang J. Principles of diffusion tensor imaging and its applications to basic neuroscience research. Neuron. 2006;51(5): 527-39.

6. Yoshikawa K, Nakata Y, Yamada K, Nakagawa M. Early pathological changes in the parkinsonian brain demonstrated by diffusion tensor MRI. J Neurol Neurosurg Psychiatry. 2004;75 (3):481-4.

7. Chan LL, Rumpel H, Yap K, Lee E, Loo HV, Ho GL, et al. Case control study of diffusion tensor imaging in Parkinson's disease. J Neurol Neurosurg Psychiatry. 2007;78(12):1383-6.

8. Matsui H, Nishinaka K, Oda M, Niikawa H, Kubori T, Udaka F. Dementia in Parkinson's disease: diffusion tensor imaging. Acta Neurol Scand. 2007;116(3):177-81.

9. Camicioli R, Fisher N. Progress in clinical neurosciences: Parkinson's disease with dementia and dementia with Lewy bodies. Can J Neurol Sci. 2004;31(1):7-21.

10. Bozzali M, Falini A, Cercignani M, Baglio F, Farina E, Alberoni M, et al. Brain tissue damage in dementia with Lewy bodies: an in vivo diffusion tensor MRI study. Brain. 2005;128(Pt 7): 1595-604.

11. Wiltshire K, Foster S, Kaye JA, Small BJ, Camicioli R. Corpus callosum in neurodegenerative diseases: findings in Parkinson's disease. Dement Geriatr Cogn Disord. 2005;20(6):345-51.

12. Hughes AJ, Daniel SE, Kilford L, Lees AJ. Accuracy of clinical diagnosis of idiopathic Parkinson's disease: a clinicopathological study of 100 cases. J Neurol Neurosurg Psychiatry. 1992;55(3):181-4.
13. American Psychiatric Association. American psychiatric association. diagnostic and statistical manual of mental disorders: DSM-IV. 4th ed. Washington DC: 1994.

14. Folstein MF, Folstein SE, McHugh PR. "Mini-mental state". A practical method for grading the cognitive state of patients for the clinician. J Psychiatr Res. 197;12(3):189-98.

15. Fahn S, Elton RL, Members of the UPDRS Development Committee. The Unified Parkinson's Disease Rating Scale. In Fahn S, Marsden CD, Calne DB, Goldstein M, eds: Recent Developments in Parkinson's Disease, Vol. 2. Florham Park, NJ: Macmillan Healthcare Information, 1987. pp. 153-163, 293-304.

16. Camicioli R, Gee M, Bouchard TP, Fisher NJ, Hanstock CC, Emery DJ, et al.Voxel-based morphometry reveals extra-nigral atrophy patterns associated with dopamine refractory cognitive and motor impairment in parkinsonism. Parkinsonism Relat Disord. 2009;15(3): 187-95.

17. Acharya HJ, Bouchard TP, Emery DJ, Camicioli RM. Axial signs and magnetic resonance imaging correlates in Parkinson's disease. Can J Neurol Sci. 2007;34(1):56-61.

18. Mori S, Crain BJ, Chacko VP, van Zijl PC. Three-dimensional tracking of axonal projections in the brain by magnetic resonance imaging. Ann Neurol. 1999;45(2):265-9.

19. Shrout PE, Fleiss JL. Intraclass correlations: uses in assessing rater reliability. Psychol Bull. 1979;86:420-8

20. Matsui H, Nishinaka K, Oda M, Niikawa H, Komatsu K, Kubori T, et al. Wisconsin Card Sorting Test in Parkinson's disease: diffusion tensor imaging. Acta Neurol Scand. 2007;116(2): $108-12$.

21. Matsui H, Nishinaka K, Oda M, Niikawa H, Komatsu K, Kubori T, et al. Depression in Parkinson's disease. Diffusion tensor imaging study. J Neurol. 2007;254(9):1170-3.

22. Gattellaro G, Minati L, Grisoli M, Mariani C, Carella F, Osio M, et al. White matter involvement in idiopathic Parkinson disease: a diffusion tensor imaging study. AJNR Am J Neuroradiol. 2009; 30(6):1222-6.

23. Tessa C, Giannelli M, Della Nave R, Lucetti C, Berti C, Ginestroni A, et al. A whole-brain analysis in de novo Parkinson disease. AJNR Am J Neuroradiol. 2008;29(4):674-80.

24. Karagulle Kendi AT, Lehericy S, Luciana M, Ugurbil K, Tuite P. Altered diffusion in the frontal lobe in Parkinson disease. AJNR Am J Neuroradiol. 2008;29(3):501-5.

25. Scherfler C, Schocke MF, Seppi K, Esterhammer R, Brenneis C, Jaschke W, et al. Voxel-wise analysis of diffusion weighted imaging reveals disruption of the olfactory tract in Parkinson's disease. Brain. 2006;129(Pt 2):538-42.

26. Zhang K, Yu C, Zhang Y, Wu X, Zhu C, Chan P, et al. Voxel-based analysis of diffusion tensor indices in the brain in patients with Parkinson's disease. Eur J Radiol. 2009 Aug 17. [Epub ahead of print].

27. Vaillancourt DE, Spraker MB, Prodoehl J, Abraham I, Corcos DM, Zhou XJ, et al. High-resolution diffusion tensor imaging in the substantia nigra of de novo Parkinson disease. Neurology. 2009; 72(16): 1378-84.

28. Menke RA, Scholz J, Miller KL, Deoni S, Jbabdi S, Matthews PM, et al. MRI characteristics of the substantia nigra in Parkinson's disease: a combined quantitative T1 and DTI study. Neuroimage. 2009;47(2):435-41.

29. Aravamuthan BR, Stein JF, Aziz TZ. The anatomy and localization of the pedunculopontine nucleus determined using probabilistic diffusion tractography. Br J Neurosurg. 2008;22 Suppl 1:S25-32.

30. Malykhin N, Concha L, Seres P, Beaulieu C, Coupland NJ. Diffusion tensor imaging tractography and reliability analysis for limbic and paralimbic white matter tracts. Psychiatry Res. 2008; 164(2):132-42.

31. Yoshiura T, Mihara F, Ogomori K, Tanka A, Kaneko K, Masuda K. Diffusion tensor in posterior cingulate gyrus: correlation with cognitive decline in Alzheimer's disease. NeuroReport. 2002;13 (17):2299-302

32. Nakata Y, Sato N, Nemoto K, Abe O, Shikakura S, Arima K, et al. Diffusion abnormality in the posterior cingulum and hippocampal volume: correlation with disease progression in Alzheimer's disease. Magn Reson Imag. 2009;27(3):347-54. 